Homepage: http://epubs.icar.org.in/ejournal/index.php/JWR

\title{
Identification of physiological traits at seedling stage associated with salt tolerance in wheat variety $\mathrm{KH} 65$ using RILs
}

\author{
Rajni Devi ${ }^{1}$, Sewa Ram ${ }^{1}$, Ajay Verma ${ }^{1}$, Veena Pande ${ }^{2}$ and Gyanendra Pratap Singh ${ }^{1}$ \\ ${ }^{1}$ ICAR-Indian Institute of Wheat and Barley Research, Karnal, India \\ ${ }^{2}$ Kumaun University, Nainital-263001, Uttarakhand, India
}

\section{Article history}

Received: 14 May, 2018

Revised : 22 June, 2018

Accepted: 04 August, 2018

\section{Citation}

Devi R, S Ram, A Verma, V Pande and GP Singh. 2018. Identification of physiological traits at seedling stage assoiated with salt tolerance in wheat variety KH65 using RILs. Wheat and Barley Research 10(2):108-114. doi.org/ 10.25174/2249-4065/2018/79735

\section{*Corresponding author}

Email: sewaram01@yahoo.com

\begin{abstract}
Salinity is a major stress affecting production and productivity of wheat across the world. Understanding physiological traits associated with salt tolerance can help in breeding for improving wheat under salt stress. In the present investigation, physiological traits in $3^{\text {rd }}$ leaf at seedling stage and grain yield at maturity were studied in a population of RILs derived from a cross between salt tolerant (Kharchia 65) and susceptible (HD 2009) cultivars under control (pH 8.2) and sodic condition (pH 9.2) in microplots. Though, HD 2009 had higher yield under control conditions, it exhibited higher reduction in yield (44.7\%) under sodic stress as compared to KH $65(9.8 \%)$. There was asignificantly lower accumulation of $\mathrm{Na}^{+}$content and higher accumulation of $\mathrm{K}^{+}$, proline and chlorophyll content in $3^{\text {rd }}$ leaf of $\mathrm{KH}$ 65 as compared to $\mathrm{HD} 2009$ under sodic stress. $\mathrm{Na}^{+}$content exhibited significant negative correlation $(P<0.01)$ while $\mathrm{K}^{+} / \mathrm{Na}^{+}$ratio, proline content and chlorophyll content showed significant positive correlation $(\mathbf{P}<0.01)$ with grain yield $(\mathrm{GY})$ under sodic condition. First and second principal component analysis (PCA) explained total variation of 66.43\% (PCI 50.18 \% and PCII 16.25\%) among different traits under sodic conditions. $\mathrm{Na}^{+}$content made independent group with strong negative correlation with grain yield and $\mathrm{K}^{+} / \mathrm{Na}^{+}$ratio while proline content and thousand grain weight (TGW) were grouped together along with GY. The study demonstrated that low $\mathrm{Na}^{+}$concentration and high $\mathrm{K}^{+} / \mathrm{Na}^{+}$ratio, proline and chlorophyll content at seedling stage are important physiological traits contributing towards yield under sodic stress. The information is useful in breeding programme of wheat for salt tolerance.
\end{abstract}

Keywords: Sodicity, wheat (Triticum aestivum L.), RILs, salt tolerance, PCA.

\section{Introduction}

Wheat is one of the most important cereal crops contributing substantially in food and nutritional security. However, production and productivity of wheat is affected by several abiotic constraints including high and low temperature, drought and salt stress. Among these stresses, salt stress is the major stress spreading worldwide and results from accumulation of soluble salts in the root zone (Ashraf and Foolad, 2007) which causes annual losses of large area of arable land (Pressarakli and Szabolcs, 1999).
Approximately, 900 million hectares of land in the world and 7 million hectares in India are salt affected areas (FAO, 2008). Among salt affected soils, sodic soilshave excess of $\mathrm{Na}^{+}$ion on exchange sites and associated with high pH (8.5-10.2) (Sharma et al., 2004). Development of salt tolerant cultivars is required as soil remediation is difficult to apply in all situations by the farmers. However, breeding for salt tolerance is difficult because of unavailability of selection criteria and complexity of 
the trait. Therefore, understanding physiological basis of salt tolerance is needed to improve wheat varieties for salt stress (Munns and Tester, 2008).

Salt stress affects all stages of plant development including germination, seedling, vegetative growth and mature stage. It adversely affects seedling establishment at early growth stages and causes yield reduction (Bahrani et al., 2012). Seedling stage can be used in selecting tolerant plants under salt stress (Aflaki et al., 2017).The present investigation was conducted to know the effect of sodic stress on physiological traits including $\mathrm{Na}^{+}$content, $\mathrm{K}^{+}$content, proline content and chlorophyll content at seedling stage in a set of 114 RIL populations developed of a cross between KH $65 \times$ HD 2009 cultivars. Kharchia 65 (KH 65) is a well-known wheat genotype tolerant to salt stress (Munns et al., 2006, Sairam et al., 2002; Rana et al., 2015) and has been used extensively throughout the world in breeding programmes. However, very little is known about the physiological basis of tolerance in $\mathrm{KH}$ 65. Several physiological changes occur in response to salt stress in plant. Understanding physiological basis of salt tolerance in $\mathrm{KH} 65$ can lead to enhanced efficiency in selection of desirable plants in breeding. This needs controlled conditions for experimentation as soil heterogeneity for salt concentration under natural conditions affect the true expression of genotype. Therefore, specially designed microplots were used in this investigation to identify physiological traits associated with salt stress in wheat.

\section{Materials and methods}

2.1. Experimental Design: $A$ microplot experiment was conducted at ICAR-Indian Institute of Wheat \& Barley Research (IIWBR), Karnal during 2015-16 crop season. A set of 114 recombinant inbred lines (RILs-F8) derived from a cross between KH 65 (salt tolerant) × HD 2009 (salt sensitive) were grown under $\operatorname{control}(\mathrm{pH} \sim 8.0)$ andsodic soil ( $\mathrm{pH} 9.2)$ conditions in microplot $(3 \mathrm{~m} \times 6 \mathrm{~m})$ with row length of $75 \mathrm{~cm}$ and row to row space of $20 \mathrm{~cm}$. Microplots were developed by adding the required amount of sodium bicarbonate $\left(\mathrm{NaHCO}_{3}\right)$ and sodium carbonate $\left(\mathrm{Na}_{2} \mathrm{CO}_{3}\right)$ to the soil. Two replications of each sample were taken for estimating $\mathrm{Na}^{+}$content $\left(\mathrm{mg}^{-\mathrm{g}} \mathrm{DW}\right), \mathrm{K}^{+}$content $\left(\mathrm{mg}^{-\mathrm{g}} \mathrm{DW}\right)$, proline content $\left(\mu^{-g} \mathrm{FW}\right)$, chlorophyll content $\left(\mathrm{mg}^{-\mathrm{g}} \mathrm{FW}\right)$ in $3^{\text {rd }}$ leaf at seedling stage and thousand grain weight $(\mathrm{g})$ and grain yield $(\mathrm{g})$ per row of $75 \mathrm{~cm}$ after harvest.
2.2. Measurement of ions: $3^{\text {rd }}$ leaf(10 days after leaf appearance) was used for the measurement of $\mathrm{Na}^{+}$and $\mathrm{K}^{+}$concentration at seedling stage. $100 \mathrm{mg}$ leaf samples were dried for $48 \mathrm{hrs}$ at $65^{\circ} \mathrm{C}$ and digested in $0.5 \mathrm{ml}$ of $0.5 \mathrm{~N} \mathrm{HNO}_{3}$ for $2 \mathrm{hrs}$ at $80^{\circ} \mathrm{C}$ as reported by Munns et al., 2010. The extract was centrifuged at $10000 \mathrm{rpm}$ for 5 minute followed by 100 times dilution of the supernatant. Concentrations of $\mathrm{Na}^{+}$and $\mathrm{K}^{+}$were measured by flame photometer using standards in the range of $0.25 \mathrm{ppm}$ to $20 \mathrm{ppm}$ and expressed on dry weight basis as milligram per gram dry weight $\left(\mathrm{mg}^{-\mathrm{g}} \mathrm{DW}\right)$.

\subsection{Measurement of Proline: Proline content of $3^{\text {rd }}$ leaf was} extracted using ninhydrin reaction method (Bates et al., 1973). $50 \mathrm{mg}$ of fresh leaf sample was homogenized in $3 \%$ sulphosalicylic acid ( $5 \mathrm{\mu l}^{\mathrm{mg}}$ fresh weight), kept on ice for 5 minutes and centrifugedat $14,000 \mathrm{~g}$ for $10 \mathrm{~min}$ at room temperature. Reaction mixture contained $200 \mu \mathrm{l}$ glacial acetic acid, $200 \mu \mathrm{l}$ ninhydrin reagent and $100 \mu \mathrm{l}$ of supernatant. Incubatethe reaction mixture for 20 min at $90^{\circ} \mathrm{C}$ in water bath then, terminate the reaction on ice. $1 \mathrm{ml}$ toluene was added in reaction mixture and mixed by vortex. The upper toluene phase was used for spectrophotometric analysis at $520 \mathrm{~nm}$. The concentration was measured using proline as the calibration standard. The proline content expressed in microgram per gram fresh weight $\left(\mu^{-g} \mathrm{FW}\right)$.

\subsection{Measurement of chlorophyll content: Chlorophyll content} was estimated by extracting $50 \mathrm{mg}$ fresh weight of the leaf material in $10 \mathrm{ml}$ dimethylsulfoxide (DMSO) (Hiscox and Israelstam, 1979). Samples were heated in an incubator at $65{ }^{\circ} \mathrm{C}$ for $4 \mathrm{~h}$ and cooled to room temperature; the absorbance of the extracts was recorded at $663 \mathrm{~nm}$. Chlorophyll content of the extract in $\mu \mathrm{g} / \mathrm{ml}$ was calculated as $\mathrm{Chl}_{\text {Total }}$ : $\left[20.2 \mathrm{x} \mathrm{A}_{645}+8.02 \mathrm{x} \mathrm{A}_{663}\right]$. Values of $\mathrm{Chl}_{\text {Total }}$ in $\mathrm{mg}^{-\mathrm{g}}$ fresh weight were obtained by multiplying the above values with "V/W x 1000", where V is volume of extract; $\mathrm{W}$ is fresh weight of sample as per Arnon (1949).

2.5. Statistical analysis: SAS software version 9.3 was used for statistical analysis for estimating correlation among different traits under control and sodicconditions. PCA was performed by Genstat software to identify the distribution of RILs vis a visdifferent traits and to identify traits contributing towards yield. 


\section{Results and Discussion}

Tolerance to salt stress is a complex biological phenomenon governed by several physiological and genetic factors, and it is growth stage specific (Haq et al. 2010). Variations in physiological traits and their inter-relationships in seedling stage, and TGW and grain yield after harvest, under sodic stressare discussed below.

3.1. Effects of salt stress on yield traits: Though HD 2009 exhibited comparatively higher grain yield (GY) under control conditions, it showed higher reduction in yield (44.7\%) under sodic conditions as compared to $\mathrm{KH} 65$ $(9.8 \%)$ (Table1). There was significantly higher GY in $\mathrm{KH}$ $65(56.0 \mathrm{~g})$ as compared to HD 2009 (35.5g) under sodic condition. Similarly, RILs also showed wide range in yield and yield reduction under sodic condition. GY varied from 21 to $88 \mathrm{~g}$ with the mean value of $50.53 \mathrm{~g}$ in RILs under control condition and from 14.85 to $70.10 \mathrm{~g}$ with the mean value of $37.17 \mathrm{~g}$ under sodic condition. There are other reports also showing wide range of reduction in yield in tolerant and sensitive cultivars from control to sodic stress condition in wheat (Akbarpour et al., 2015). There was also higher percentage of reduction in TGW in HD 2009 (23.0\%) as compared to KH 65 (9.7\%). Thus, $\mathrm{KH} 65$ exhibited tolerance to high $\mathrm{pH}$ with higher yield and TGW under sodic conditions. TGW varied from 24 to $49.6 \mathrm{~g}$ with the mean value of $39.19 \mathrm{~g}$ in RILs under control condition and from 20 to $46.05 \mathrm{~g}$ with the mean value of $36.02 \mathrm{~g}$ under sodic condition.
3.2. Effects of salt stress on ion concentrations: Though there was increase in $\mathrm{Na}^{+}$accumulation in $3^{\text {rd }}$ leaf under salt conditions, it was significantly lower in $\mathrm{KH} 65$ (6.01 $\mathrm{mg}^{-\mathrm{g}}$ DW) as compared to HD $2009\left(9.01 \mathrm{mg}^{-\mathrm{g}} \mathrm{DW}\right)$ and varied from 4.47 to $16.75 \mathrm{mg}^{-\mathrm{g}} \mathrm{DW}$ among RILs (Table 1). The important locationof $\mathrm{Na}^{+}$toxicity for most plants is the leaf blade, thus excluding $\mathrm{Na}^{+}$from the leaves blades is considered important for salt tolerance (Munns et al., 2008). In general, more of sodium is accumulated under salt stress which results into ionic imbalance, and thus affect plant metabolism (Tavakkoli et al., 2011). There was a significantly higher content of $\mathrm{K}^{+}$in $\mathrm{KH} 65\left(21.6 \mathrm{mg}^{-\mathrm{g}} \mathrm{DW}\right)$ as compared to HD 2009 (15.80 $\left.\mathrm{mg}^{-\mathrm{g}} \mathrm{DW}\right)$ under sodic condition. In RILs $\mathrm{K}^{+}$content varied from 17.01 to $46.32 \mathrm{mg}^{-\mathrm{g}} \mathrm{DW}$ with the mean value $31.25 \mathrm{mg}^{-\mathrm{g}} \mathrm{DW}$ in control and 9.13 to 28.64 $\mathrm{mg}^{-\mathrm{g}} \mathrm{DW}$ with the mean value of $18.30 \mathrm{mg}^{-\mathrm{g}} \mathrm{DW}$ in sodic condition (Table 1). Salt stress induced increase in sodium and depletion of potassium contents has also been reported earlier (Sairam et al., 2002). Ratio of $\mathrm{K}^{+} / \mathrm{Na}^{+}$was higher in KH 65 (3.18) as compared to HD 2009 (1.75) under sodic condition. High levels of $\mathrm{Na}^{+}$inhibit the $\mathrm{K}^{+}$uptake resulting into $\mathrm{K}^{+}$deficiency (Khan et al., 2009). Thus regulation of $\mathrm{K}^{+} / \mathrm{Na}^{+}$ratio has important role in imparting tolerance to salt stress in $\mathrm{KH} 65$. Optimum $\mathrm{K}^{+} / \mathrm{Na}^{+}$ratio can help in maintaining an ideal osmotic and membrane potential for cell volume regulation in plant under salt stress (ElHendawy et al. 2009). The data showed that KH 65 had low leaf $\mathrm{Na}^{+}$accumulation and relatively high $\mathrm{K}^{+}$concentration and thus exhibited higher tolerance under sodic conditions.

Table1. Means ( \pm standard error) and variation of physiological and yield traits for parental genotypes KH 65 (tolerant) and HD 2009 (susceptible), and RILs population under control (pH 8.0) and sodic condition (pH 9.2).

\begin{tabular}{|c|c|c|c|c|c|c|c|c|}
\hline \multirow{3}{*}{ Traits } & \multicolumn{4}{|c|}{ Parents } & \multicolumn{4}{|c|}{ RILs } \\
\hline & \multicolumn{2}{|c|}{ KH65 } & \multicolumn{2}{|c|}{ HD2009 } & \multirow{2}{*}{$\frac{\text { Mean } \pm \text { SD }}{\mathrm{C}}$} & \multirow{2}{*}{$\begin{array}{c}\text { Range } \\
\mathrm{C}\end{array}$} & \multirow{2}{*}{$\frac{\text { Mean } \pm S D}{S}$} & \multirow{2}{*}{$\frac{\text { Range }}{\mathrm{S}}$} \\
\hline & $\mathrm{C}$ & $\mathrm{S}$ & $\mathrm{C}$ & $\mathrm{S}$ & & & & \\
\hline $\mathrm{Na}^{+}\left(\mathrm{mg}^{-\mathrm{g}} \mathrm{DW}\right)$ & 0.98 & 6.01 & 0.88 & 9.01 & $1.21 \pm 0.34$ & $0.47-2.05$ & $9.32 \pm 1.21$ & $4.47-16.75$ \\
\hline $\mathrm{K}^{+}\left(\mathrm{mg}^{-\mathrm{g}} \mathrm{DW}\right)$ & 36.67 & 21.6 & 34.66 & 15.8 & $31.25 \pm 1.19$ & $17.01-46.32$ & $18.30 \pm 1.37$ & $9.13-28.64$ \\
\hline $\mathrm{K}^{+} / \mathrm{Na}^{+}$ & 37.42 & 3.18 & 39.39 & 1.75 & $29.08 \pm 2.39$ & $21.90-35.94$ & $2.37 \pm 0.65$ & $0.82-5.82$ \\
\hline Proline (ug ${ }^{-g}$ FW) & 0.76 & 2.15 & 0.61 & 0.91 & $0.57 \pm 0.27$ & $0.22-0.99$ & $3.12 \pm 3.81$ & $0.60-2.50$ \\
\hline CHL Content $\left(\mathrm{mg}^{-\mathrm{g}} \mathrm{FW}\right)$ & 41.09 & 38.51 & 38.63 & 29.1 & $34.99 \pm 1.05$ & $23.0-48.75$ & $31.69 \pm 0.82$ & 19.94-39.89 \\
\hline TGW (g) & 39.9 & 36 & 39 & 30.2 & $39.19 \pm 0.78$ & $24.0-49.6$ & $36.02 \pm 1.13$ & 20.0-46.05 \\
\hline GY (g) & 62.1 & 56 & 64.2 & 35.5 & $50.53 \pm 2.27$ & $21.0-88.0$ & $37.17 \pm 2.62$ & $14.85-70.10$ \\
\hline
\end{tabular}

C-Control; S-Sodic; $\mathrm{Na}^{+}$-Sodium content; $\mathrm{K}^{+}$-Potassium content; $\mathrm{K}^{+} / \mathrm{Na}^{+}$-Potassium sodium ratio; CHL- Chlorophyll content; TGW- Thousand grain weight; GY- Grain yield per row of $75 \mathrm{~cm}$. 


\subsection{Effects of salt stress on proline accumulation and chlorophyll} content: Though, there was significant increase in proline content under sodic condition in both the cultivars, it was significantly higher in $\mathrm{KH} 65\left(2.15 \mu \mathrm{g}^{-\mathrm{g}} \mathrm{FW}\right)$ as compared to HD $2009\left(0.91 \mu \mathrm{g}^{-\mathrm{g}} \mathrm{FW}\right)$.In RILs proline content varied from 0.22 to $0.99 \mu^{-g} \mathrm{FW}$ with the mean value $0.57 \mu \mathrm{g}^{-\mathrm{g}} \mathrm{FW}$ in control and 0.60 to $2.50 \mu^{-g} \mathrm{FW}$ with the mean value of $3.12 \mu \mathrm{g}^{-\mathrm{g}} \mathrm{FW}$ in sodic condition (Table 1). Accumulation of proline content under stress protects the cell by balancing the osmoticstrength of cytosol with that of vacuole and externalenvironment (Gadallah et al., 1995). In addition, it has role in protecting enzymes activity under stress conditions. The data further support various earlier studies showing a positive role of proline in salt tolerance (Khan et al., 2009; Ashraf and Foolad, 2007; Munns, 2005). Chlorophyll content was higher in KH 65 (38.51 mg-g FW) as compared to HD 2009 (29.10 $\mathrm{mg}^{-\mathrm{g} F W}$ ) under sodic condition (Table 1). In RILs chlorophyll content varied from 23.0 to $48.75 \mathrm{mg}^{-\mathrm{g}} \mathrm{FW}$ with the mean value 34.99 in control and 19.94 to $39.89 \mathrm{mg}^{-\mathrm{g}} \mathrm{FW}$ with the mean value of $31.69 \mathrm{mg}^{-\mathrm{g}} \mathrm{FW}$ in sodic condition. Other reports indicated that the high $\mathrm{Na}+$ lines lost chlorophyll more rapidly and died earlier than the low $\mathrm{Na}^{+}$lines (Munns et al. 2006; Oyiga et al., 2016). Azadi et al. (2011) observed decrease in chlorophyll content at $150 \mathrm{mMNaCl}$ treatment as compared to control in wheat. Similarly, Sai Ram et al., 2002 also suggested the role of chlorophyll in imparting tolerance to salt stress in crop plants at seedling stage.
3.4. Correlation between various traits: A wide range of correlations wereobservedamong various traits under control and sodic conditions (Table 2). Significant positive correlations were found between GY and TGW under control $(\mathrm{r}=0.339, \mathrm{P}<0.01)$ and sodic $(\mathrm{r}=0.569$, $\mathrm{P}<0.001)$ conditions. Though $\mathrm{Na}+$ content showed no correlation with GY under control condition,it exhibited significantly negative correlation $(\mathrm{r}=-0.240, \mathrm{P}<0.01)$ under sodic condition (Table 2). Other studies also showed negative correlation of $\mathrm{Na}^{+}$with GY under salt stress (Cuin et al., 2008). Though $\mathrm{K}^{+}$content did not show any correlation with GY under sodiccondition, it exhibited significant positive correlation with $\mathrm{K}^{+} / \mathrm{Na}^{+}$ratio, proline content, chlorophyll content and TGW. Furthermore, biochemical traits includes $\mathrm{K}^{+} / \mathrm{Na}^{+}$ratio, proline content and chlorophyll content showed positive correlation with GY under sodic condition (Table 2). This is in agreement with some of the studies indicating role of $\mathrm{K}^{+} / \mathrm{Na}^{+}$ratio, proline and chlorophyll in imparting salt tolerance (Goudarzi et al., 2008; Thalji et al., 2007). Significant positive correlation between proline and GY indicated the positive role of proline in combating salt stress by its increased accumulation under stressed condition. The data indicated that low $\mathrm{Na}^{+}$accumulation and high $\mathrm{K}^{+}$/ $\mathrm{Na}^{+}$ratio, proline content and chlorophyll content are important traits for tolerance in seedling stage. Screening for the tolerance at seedling stage may be helpful in finding tolerant genotypes with high yield potential under saltstress (Aflaki et al., 2017).

Table 2. Correlation between different traits under control (lower diagonal) and sodic (above diagonal) conditions in RILs of the cross between KH 65 and HD 2009

\begin{tabular}{lccccccc}
\hline Trait name & $\mathrm{Na}^{+}$ & $\mathrm{K}^{+}$ & $\mathrm{K}^{+} / \mathrm{Na}^{+}$ & $\mathrm{P}$ & $\mathrm{CHL}$ & $\mathrm{TGW}$ & $\mathrm{GY}$ \\
\hline $\mathrm{Na}^{+}$ & 1 & $-0.303^{* *}$ & $-0.703^{* * *}$ & $-0.491^{* *}$ & $-0.356^{* *}$ & $-0.431^{* *}$ & $-0.240^{* *}$ \\
$\mathrm{~K}^{+}$ & $-0.244^{* *}$ & 1 & $0.829^{* * *}$ & $0.449^{* *}$ & 0.108 & $0.333^{* *}$ & 0.176 \\
$\mathrm{~K}^{+} / \mathrm{Na}^{+}$ & $-0.847^{* * *}$ & $0.590^{* * *}$ & 1 & $0.558^{* * *}$ & $0.303^{* *}$ & $0.483^{* *}$ & $0.264^{* *}$ \\
Proline & -0.114 & $0.336^{* *}$ & $0.200^{*}$ & 1 & $0.217^{*}$ & $0.544^{* * *}$ & $0.298^{* *}$ \\
$\mathrm{CHL}$ & 0.052 & $0.357^{* *}$ & 0.108 & $0.349^{* *}$ & 1 & $0.252^{* *}$ & $0.260^{* *}$ \\
$\mathrm{TGW}$ & -0.063 & $0.184^{*}$ & 0.165 & 0.003 & 0.045 & 1 & $0.569^{* * *}$ \\
$\mathrm{GY}$ & -0.044 & -0.047 & 0.035 & 0.063 & 0.059 & $0.339^{* *}$ & 1 \\
\hline
\end{tabular}

$\mathrm{Na}^{+}$-Sodium content; $\mathrm{K}^{+}$-Potassium content; $\mathrm{K}^{+} / \mathrm{Na}^{+}$-Potassium sodium ratio; CHL- Chlorophyll content; TGWThousand grain weight; GY- Grain yield. ${ }^{*} \mathrm{P}<0.05 ;{ }^{* *} \mathrm{P}<0.01 ;{ }^{* * *} \mathrm{P}<0.001$ 
3.5. Principal component analysis (PCA): Principal component analysis (PCA) is another way of understanding the interrelationships between traits and thus can identify screening criteria under sodic stress. Figure 1 shows the principal component analysis (PCA) of all seven traits under control conditions. Based on PCA, the first two components explained 54.02 \% (PC1, 34.43\%; PC2, $19.59 \%)$ of the total variation among different traits under control condition (Figure 1). However, under sodic condition the first and second PCA explained total variation of $66.43 \%$ (PCI $50.18 \%$ and PCII $16.25 \%$ ) among different traits (Figure 2).Under control condition chlorophyll and proline content grouped together with GY while chlorophyll and TGW were grouped with GY under sodic conditions. The $\mathrm{K}^{+}$content and TGW were grouped together in control condition and showed correlation with GY (Figure1). While under sodic condition $\mathrm{K}^{+}$ content, $\mathrm{K}^{+} / \mathrm{Na}^{+}$ratio and proline content were grouped togetherand thus can be used interchangeable for selecting desirable genotypes under sodiccondition. $\mathrm{Na}^{+}$ content showed independent group with strong negative correlation with grain yield and thus suggests that the exclusion of toxic ions may be an important component of salt tolerance in wheat as reported by EL-Hendawy et al., 2017.

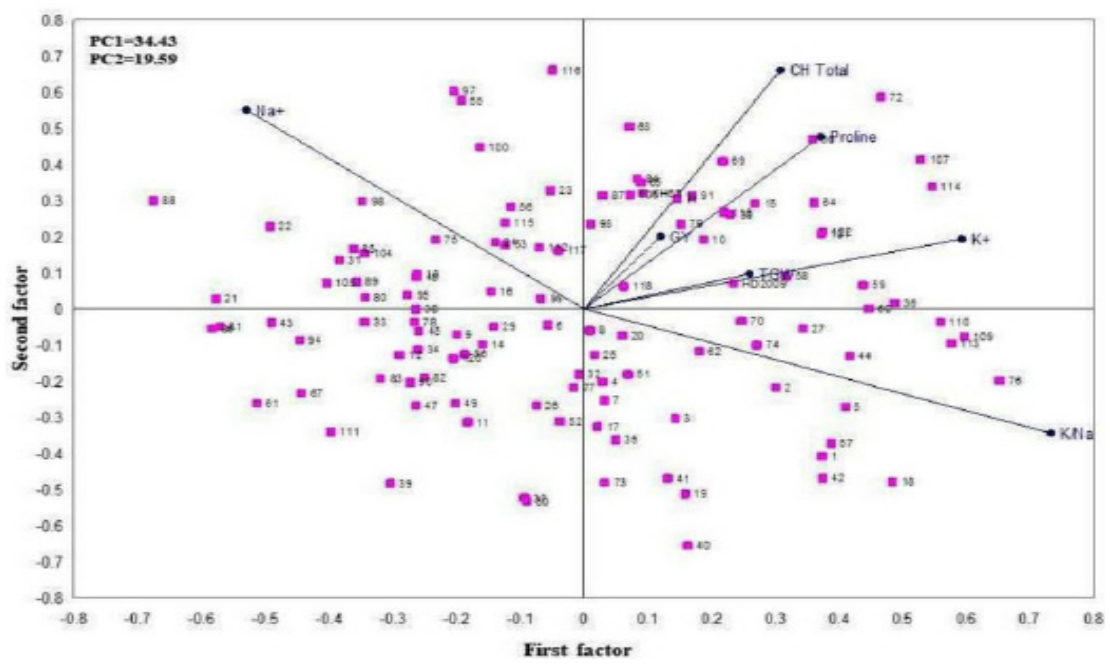

Figure 1. Vector view of the biplot showing interrelationships among traits under control conditions. $\mathrm{Na}^{+}$- Sodium content; $\mathrm{K}^{+}$Potassium content; $\mathrm{K}^{+} / \mathrm{Na}^{+}$- Potassium sodium ratio; P- Proline content; $\mathrm{CH}$ Total- Chlorophyll content; TGW- Thousand grain weight; GY- Grain yield.

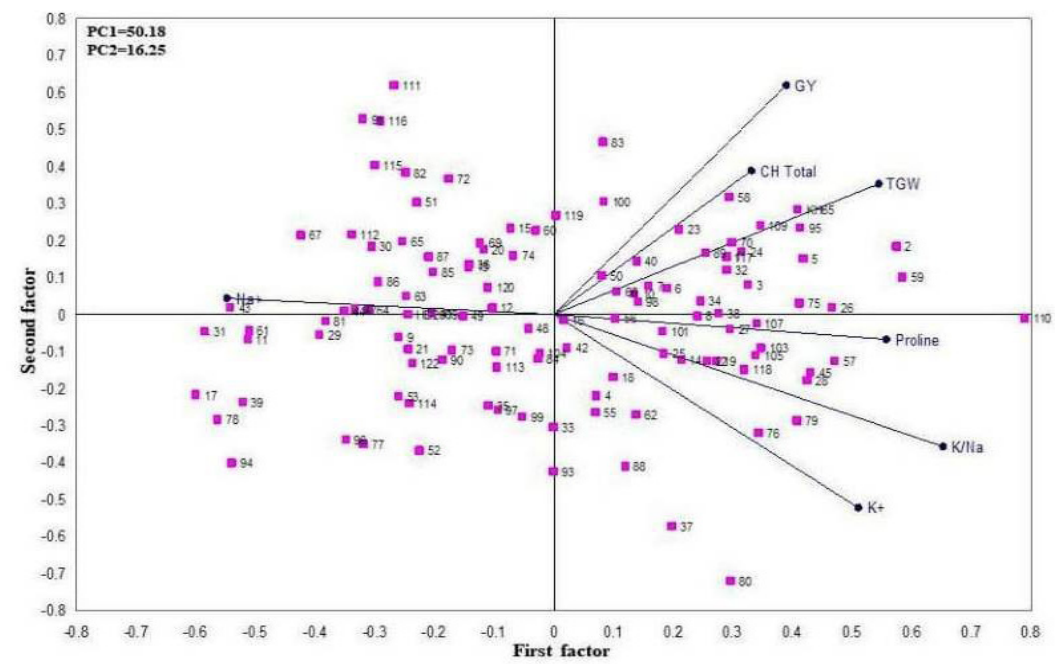

Figure 2. Vector view of the biplot showing interrelationships among traits under sodic stress conditions. $\mathrm{Na}^{+}-$Sodium content; $\mathrm{K}^{+}$-Potassium content; $\mathrm{K}^{+} / \mathrm{Na}^{+}$- Potassium sodium ratio; P- Proline content; $\mathrm{CH}$ Total- Chlorophyll content; TGW- Thousand grain weight; GY- Grain yield. 
In conclusion, significant positive correlations were observed between grain yield and $\mathrm{K}^{+} / \mathrm{Na}^{+}$ratio, proline content and chlorophyll content. While $\mathrm{Na}^{+}$content showed negative correlation with grain yield under sodic stress. This demonstrated that low $\mathrm{Na}^{+}$concentration and high proline and chlorophyll contentat seedling stage are important physiological traits contributing towards yield under salt stress and thus can be used as selection criteria in breeding programme.

\section{Acknowledgements}

The authors sincerely acknowledge the support and facilities provided by ICAR-IIWBR, Karnal under network project for salt tolerance.

\section{References}

1. Aflaki F, M Sedghi, A Pazuki and M Pessarakli. 2017. Investigation of seed germination indices for early selection of salinity tolerant genotypes: A case study in wheat. Emirates Journal of Food and Agriculture 29(3): 222-226.

2. Akbarpour OA, H Dehghani and MJ Rousta. 2015. Evaluation of salt stress of Iranian wheat germplasm under field conditions. Crop and Pasture Science 66:770781.

3. Arnon DI. 1949. Copper enzymes in isolated chloroplasts, polyphenoxidase in beta vulgaris. Plant physiology 24: 1-15.

4. Ashraf M and MA Foolad. 2007. Improving plant abiotic-stress resistance by exogenous application of osmo-protectants glycine betaine and proline. Environmental and Experimental Botany 59: 206-216.

5. Azadi A, E Majidi Haravan, SB Mohammadi, F Moradi, B NaKHoda, M Vahabzade and M Mardi. 2011. African Journal of Biotechnology 10(60): 12875-12881.

6. Bahrani A and M Hagh Joo.2012. Response of some wheat (Triticumaestivum L.) genotype to salinity at germination and early seedling stages. World Applied Sciences Journal 16(4): 599-609.

7. Bates LS and RP Waklren. 1973. Rapid determination of free proline water stress studies: 8nd I.D. Te8re. Plant Soil 39:205-207.

8. Cuin TA, SA Betts, R Chalmandrier and S Shabala. 2008. A root's ability to retain $\mathrm{K}^{+}$correlates with salt tolerance in wheat. Journal of Experimental Botany 59: 2697-2706.
9. EL-Hendawy SE, Y Ruan, Y Hu and U Schmidhalter. 2009. A comparison of screening criteria for salt tolerance in wheat under field and controlled environmental conditions. Journal Agronomy and Crop Science 195(5): 356-367.

10. El-Hendawy SE, WM Hassan, NA Al-Suhaibani, Y Refay and KA. Abdella. 2017. Comparative performance of multivariable agro-physiological parameters for detecting salt tolerance of wheat cultivars under simulated saline field growing conditions. Frontiers in Plant Science 8(435): 1-15.

11. FAO. 2008. FAO land and plant nutrition management service. http://www.fao.org/ag/agI/agII/spush.

12. Gadallah MAA. 1995. Effect of water stress, abscicic acid and proline on cotton plants. Journal of Arid Environment 30: 315.

13. Goudarzi M and H Pakniyat. 2008. Evaluation of wheat cultivars under salinity stress based on some agronomic and physiological traits. Journal of Agriculture and social science 4: 35-8.

14. Haq T, J Gorham, J Akhtar, N Akhtar and KA Steele. 2010. Dynamic quantitative trait loci for salt stress components on chromosome 1 of rice. Functional Plant Biology 37: 634-645.

15. Hiscox JD and GF Israelstam. 1979. A method for the extraction of chlorophyll from leaf tissue without maceration. Canadian Journal of Botany 57(12): 13321334 .

16. Khan MA, MU Shirazi, MA KHan, SM Mujtaba, E Islam, S Mumtaz, A Shereen, RU Ansari and MY Ashraf. 2009. Role of proline, $\mathrm{K} / \mathrm{Na}$ ratio and chlorophyll content in salt tolerance of wheat (Triticum aestivum L.). Pakistan Journal of Botany 41: 633-638.

17. Munns R and M Tester. 2008. Mechanisms of salinity tolerance. Annual Review of Plant Biology 59: 651-681.

18. Munns R, PA Wallace, NL Teakle and TD Colmer. 2010. Measuring soluble ion concentrations $\left(\mathrm{Na}^{+}, \mathrm{K}^{+}\right.$, $\mathrm{Cl}^{-}$) in salt-treated plants. R. Sunkar (ed.), Plant Stress Tolerance, Methods and Protocols. Springer chapter 23: 371-82.

19. Munns R. 2005. Genes and salt tolerance: bringing them together. New Physiologist 167(3): 645-663.

20. Munns, R, RA James and A Lauchli. 2006. Approaches to increasing the salt tolerance of wheat and other cereals. Journal of Experimental Botany 57:1025-1043.

21. Oyiga BC, RC Sharma, J Shen, MBaum, FC Ogbonnaya, $\mathrm{J}$ Leon and A Ballvora. 2016. Identification and characterization of salt tolerance of wheat germplasm using a multivariable screening approach. Journal of Agronomy and Crop Science 202: 472-485. 
22. Pessarakli M and I Szabolcs. 1999. Soil salinity and sodicity as particular plant/crop stress factors. In: Pessarakli, ed. Handbook of Plant and Crop Stress. 3-21. CRC Taylor and Francis Group, New York, NY, USA.

23. Rana V, S Ram, K Nehra and I Sharma. 2015. Differential expression analysis of salt stress related genes TaSRG and TaRUB1 in contrasting wheat genotypes. Journal of Wheat Research 7(1): 71-73.

24. Sairam RK and GC Srivastava. 2002. Effects of zinc and ascorbic acid application on the growth and photosynthetic pigments of millet plants grown under different salinity. Plant Science 162: 897-904.
25. Sharma RC, BRM Rao and RK Saxena. 2004. Salt affected soils in India current assessment. In: Advances in sodic land reclamation. International Conferenceon Sustainable Management of Sodic Lands, 9-14 February, Lucknow, India, 1-26.

26. Tavakkoli E, F Fatehi, S Coventry, P Rengasamy and GK McDonald. 2011. Additive effects of $\mathrm{Na}+$ and $\mathrm{Cl}-$ ions on barley growth under salinity stress. Journal of Experimental Botany 62(6): 2189-2203.

27. Thalji T and G Shalaldeh. 2007. Screening wheat and barley genotype for salinity resistance. Journal of Agronomy 6(1): 75-78. 